\title{
Metastability of Palladium Carbide Nanoparticles during Hydrogen Release from Liquid Organic Hydrogen Carriers
}

Received 00th January 20xx, Accepted 00th January 20xx DOI: $10.1039 / x 0 x \times 00000 x$
Ralf Schuster, ${ }^{\mathrm{a}}$ Manon Bertram, ${ }^{\mathrm{a}}$ Henning Runge, ${ }^{\mathrm{b}}$ Simon Geile, ${ }^{\mathrm{b}}$ Simon Chung, ${ }^{\mathrm{b}}$ Vedran Vonk, ${ }^{\mathrm{b}}$ Heshmat Noei, ${ }^{\mathrm{b}}$ Agnieszka Poulain, ${ }^{\mathrm{c}}$ Yaroslava Lykhach, ${ }^{*, a}$ Andreas Stierle, ${ }^{\mathrm{b}, \mathrm{d}}$ and Jörg Libuda*,a

Efficient hydrogen release from liquid organic hydrogen carriers (LOHCs) requires a high level of control over the catalytic properties of supported noble metal nanoparticles. Here, the formation of carbon-containing phases under operation conditions has a direct influence on the activity and selectivity of the catalyst. We studied the formation and stability of carbide phases using well-defined $\mathrm{Pd} / \alpha-\mathrm{Al}_{2} \mathrm{O}_{3}(0001)$ model catalysts during dehydrogenation of a model LOHC, methylcyclohexane, in a flow reactor by in-situ high-energy grazing incidence X-ray diffraction. The phase composition of supported Pd nanoparticles was investigated as a function of particle size and reaction conditions. Under operating conditions, we detected the formation of a $\mathrm{Pd}_{x} \mathrm{C}$ phase followed by its conversion to $\mathrm{Pd}_{6} \mathrm{C}$. The dynamic stability of the $\mathrm{Pd}_{6} \mathrm{C}$ phase results from the balance between uptake and release of carbon by the supported Pd nanoparticles in combination with the thermodynamically favorable growth of carbon deposits in the form of graphene. For small Pd nanoparticles (6 $\mathrm{nm}$ ), the $\mathrm{Pd}_{6} \mathrm{C}$ phase is dynamically stable under low flow rate of reactants. At the high reactant flow, the $\mathrm{Pd}_{6} \mathrm{C}$ phase decomposes shortly after its formation due to the growth of graphene. Structural analysis of larger Pd nanoparticles (15 $\mathrm{nm}$ ) reveals the formation and simultaneous presence of two types of carbides, $\mathrm{Pd}_{\mathrm{x}} \mathrm{C}$ and $\mathrm{Pd}_{6} \mathrm{C}$. Formation and decomposition of $\mathrm{Pd}_{6} \mathrm{C}$ proceeds via a $\mathrm{Pd}_{x} \mathrm{C}$ phase. After an incubation period, growth of graphene triggers the decomposition of carbides. The process is accompanied by segregation of carbon from the bulk of the nanoparticles to the graphene phase. Notably, nucleation of graphene is more favorable on bigger Pd nanoparticles. Our studies demonstrate that metastability of palladium carbides associated with dynamic formation and decomposition of the $\mathrm{Pd}_{6} \mathrm{C}$ and $\mathrm{Pd}_{\mathrm{x}} \mathrm{C}$ phases is an intrinsic phenomenon in LOHC dehydrogenation on Pd-based catalysts and strongly depends on particle size and reaction conditions.

\section{Introduction}

Liquid organic hydrogen carriers (LOHCs) enable storage of energy obtained from intermittent renewable sources such as wind and solar power. ${ }^{1-3}$ The LOHC technology involves reversible hydrogenation and dehydrogenation of heterocyclic organic compounds which are liquid in pure form or in the form of mixtures. ${ }^{2-4} \quad$ Typically, N-ethylcarbazole, indole, methylcyclohexane, or dibenzyltoluenes store about 5-8 wt\% hydrogen at ambient conditions. . $^{5-6}$ The stored hydrogen is released by dehydrogenation of the LOHC over a noble metal catalyst at elevated temperatures. The latest research progress in the LOHC technology and development of the LOHC catalysts has been summarized in recent reviews (see e.g. refs. 7-10).

\footnotetext{
a.Interface Research and Catalysis, ECRC, Friedrich-Alexander-Universität ErlangenNürnberg, Egerlandstraße 3, 91058 Erlangen, Germany.

b. Deutsches Elektronen-Synchrotron DESY, Notkestrasse 85, 22607 Hamburg, Germany.

European Synchrotron Radiation Facility, 71 Avenue des Martyrs, 38000 Grenoble, France.

d. Fachbereich Physik, Universität Hamburg, Jungiusstrasse 11, 20355 Hamburg, Germany.

tElectronic Supplementary Information (ESI) available: [XRR, particle size distribution based on SEM, analysis of overlapping intensities of the Bragg reflection and Debye-Scherrer ring in $2 \mathrm{D}$ reciprocal space maps obtained from $15 \mathrm{~nm} \mathrm{Pd} / \alpha$ $\mathrm{Al}_{2} \mathrm{O}_{3}(0001)$ model catalyst]. See DOI: $10.1039 / x 0 x x 00000 x$
}

Previously, the detailed mechanism of LOHC dehydrogenation was investigated using model catalysts such as well-ordered $\mathrm{Pt}(111)$ and $\mathrm{Pd}(111)$ single crystals $\mathrm{s}^{6,11-14}$ and well-defined $\mathrm{Pt}$ and Pd supported nanoparticles. ${ }^{15-17}$ It was found that dehydrogenation of both homocyclic and N-heterocyclic LOHCs involves multiply dehydrogenated intermediates. The complete unloading of LOHCs is challenging because of kinetic and thermodynamic limitations and, to some extent, may also yield carbonaceous byproducts. 6,11 For instance, dehydrogenation of methylcyclohexane on $\mathrm{Pt}(111)$ involves $\pi$-allylic species which dehydrogenate to a phenyl ring. However, this step is accompanied by a $\mathrm{C}-\mathrm{H}$ bond scission in methyl group resulting in benzyl. ${ }^{13}$ This undesired reaction impedes the desorption of fully unloaded counterpart of methylcyclohexane, toluene. Generally, further dehydrogenation of phenyl rings and $\mathrm{C}-\mathrm{H}$ bond scission in methyl/methylene functional groups upon unloading of related LOHCs (e.g. dicyclohexylmethane) yields similar decomposition fragments which are the main source of the surface carbon above $450 \mathrm{~K}$ on both $\mathrm{Pt}(111)$ and $\mathrm{Pd}(111) .{ }^{11}$ With respect to the dehydrogenation efficiency, palladium is among the most efficient catalysts for LOHC dehydrogenation. It was suggested that the presence of co-adsorbates and their diffusion into the subsurface have a direct influence on the mechanism of LOHC dehydrogenation over Pd catalyst. ${ }^{11}$ Diffusion of hydrogen and carbon into the bulk of $\mathrm{Pd}$ is well 
documented in literature and the influence of the corresponding hydride and carbide phases on the activity and selectivity of the catalyst has been widely discussed. ${ }^{18-22}$ Under the conditions of LOHC dehydrogenation, hydrogen diffusion into the Pd bulk is suppressed by the low stability of $\beta$ hydride phases above $500 \mathrm{~K} .{ }^{24}$ However, the formation of surface carbon and its diffusion into the bulk in this temperature range is of particular interest. ${ }^{25-27}$ In the limit of low carbon concentration, diffusion into the bulk is thermodynamically favorable. ${ }^{28-32}$ In particular, it has been shown that subsurface diffusion is facile on stepped surfaces and on nanoparticles. ${ }^{33-34}$ At higher carbon concentration, however, density functional theory (DFT) predicts a competition between the diffusion into the subsurface region and the formation of carbon clusters on the surface. ${ }^{34-35}$ In the bulk, carbon atoms occupy interstitial octahedral sites, giving rise to an increase of the lattice parameter. ${ }^{36-38}$ Typically, two carbide phases are observed, which differ with respect to carbon content, i.e. $\alpha-P d_{x} C(1-2 \% \quad C)$ and $\beta-P d_{x} C(11-16 \% \quad C) .32$ Dissolution of carbon leads to formation of $\alpha-\mathrm{Pd}_{x} \mathrm{C}$ which is considered the precursor to the $\beta-P d_{x} C$ phase. However, even the most stable palladium carbide phase, $\mathrm{Pd}_{6} \mathrm{C}$, was found to be thermodynamically less favorable with respect to graphite. ${ }^{29} \mathrm{It}$ was argued that the formation of carbide occurs because the growth of graphene is delayed due to the large critical size of nucleus (about $5 \mathrm{~nm}$ as predicted on $\mathrm{Pd}(100)$ ). ${ }^{29}$ At the onset of graphene nucleation, the precursor structures consisting of carbon filaments with a length of a few nanometers were observed on supported Pd nanoparticles. ${ }^{30-31}$ It is not clear, however, whether the nucleation of graphene or its precursor structures eventually leads to decomposition of the carbide phase. Based on DFT calculations, the graphene adsorption on the carbide surface is slightly less energetically favored with respect to the pure $\operatorname{Pd}(111)$ surface. ${ }^{30}$ Although carbon obtained by the decomposition of hydrocarbons at the surface is considered the main source, ${ }^{31}$ alternative mechanisms of graphene growth involving carbon segregation from the bulk were also proposed. ${ }^{39}$

In this work, we investigate the formation of palladium carbide phases using well-defined $\mathrm{Pd} / \alpha-\mathrm{Al}_{2} \mathrm{O}_{3}(0001)$ model catalysts. We employ high-energy grazing incidence $\mathrm{X}$-ray diffraction $(\mathrm{HE}$ GIXRD) under the conditions of catalytic LOHC dehydrogenation to monitor the phase composition of supported $\mathrm{Pd}$ nanoparticles as a function of particle size and reactant flow rate. HE-GIXRD is a powerful method to study changes of the lattice parameter and the formation of new phases in supported noble metal nanoparticles under operando conditions. ${ }^{40-47}$ Using synchrotron radiation, we reach a temporal resolution on the order of $1 \mathrm{~s}$ in the in-situ experiment. As a model LOHC, we use methylcyclohexane which has a similar surface chemistry as the heteroatom-free LOHCs that are currently favored in technical applications (mixtures of dibenzyltoluenes ${ }^{8-9}$ ). Our study shows that the phase composition is highly dynamic under operation conditions. The formation and decomposition of carbon-containing phases are controlled by kinetic and thermodynamic effects and depend strongly on the particle size.

\section{Experimental}

The high-energy grazing incidence X-ray diffraction (HE-GIXRD) study was performed at Beamline ID31 at the European Synchrotron Radiation Facility (ESRF), Grenoble, France. GIXRD patterns were recorded with an X-ray photon energy of $78 \mathrm{keV}$ using a high-energy $2 \mathrm{D}$ detector Pilatus $3 \mathrm{X}$ CdTe $2 \mathrm{M}$ with a pixel size of 172 microns. The experiments were performed in a flow reactor (Leiden Probe Microscopy) similar to this described in ref. 48. The total pressure and the gas composition in the flow reactor were controlled by means of a mass-flow-controlled gas dosing system.

Well-defined $\mathrm{Pd} / \alpha-\mathrm{Al}_{2} \mathrm{O}_{3}(0001)$ model catalysts were prepared in an UHV setup at the DESY NanoLab. ${ }^{49}$ Briefly, the $\alpha$ $\mathrm{Al}_{2} \mathrm{O}_{3}(0001)$ substrates were first degassed at $873 \mathrm{~K}$ for two hours. Subsequently, the substrates were exposed to an oxygen cracker $\left(p_{02}=1 \times 10^{-7}\right.$ mbar, $\mathrm{T}=748 \mathrm{~K}$ ) to heal the oxygen vacancies. Finally, Pd metal was deposited in UHV by means of physical vapor deposition (PVD) from an electron beam evaporator at a deposition rate of $3.5 \times 10^{13}$ atoms $\times \mathrm{cm}^{-2} \times \mathrm{s}^{-1}$

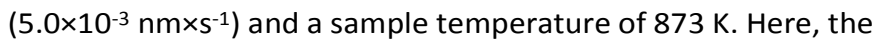
deposition rate was determined based on the X-ray reflectometry (XRR) analysis and the deposition time (see Supporting Information, Figure $\mathrm{S} 1$ ).

Two $\mathrm{Pd} / \alpha-\mathrm{Al}_{2} \mathrm{O}_{3}(0001)$ samples were prepared with apparent average diameters of the supported Pd nanoparticles of 6 and $15 \mathrm{~nm}$ as determined by a Scherrer analysis of the full width at half maximum (FWHM) of the $\mathrm{Pd}(111)$ Bragg peaks. ${ }^{50}$ Here, the apparent mean particle sizes were determined by averaging over all orientations obtained from the radial analysis of the 2D diffraction patterns (vide infra) under assumption of a spherical shape of the Pd nanoparticles. Note, that further line broadening effects like strain were neglected.

The size distribution of the Pd nanoparticles was studied by means of Scanning Electron Microscopy (SEM) (see Supporting Information, Figure S2). The analysis of the SEM images was performed with the software ImageJ. Based on the size distribution histogram, the average diameter of the $\mathrm{Pd}$ nanoparticles is $14.2 \pm 3.5 \mathrm{~nm}$. This value is in a good agreement with the size of $\mathrm{Pd}$ nanoparticles determined by a Scherrer analysis. The corresponding particle density is $2.7 \times 10^{15} \mathrm{~m}^{-2}$.

The samples were transferred into the flow reactor under ambient atmosphere and cleaned in-situ before each experiment by oxidation and reduction cycles. Specifically, the cycles consisted of $10 \mathrm{~min}$ exposure to $\mathrm{O}_{2}\left(10^{-5} \mathrm{mbar}\right)$ at $670 \mathrm{~K}$ followed by a reduction with $\mathrm{H}_{2}\left(10^{-5} \mathrm{mbar}\right)$ at $620 \mathrm{~K}$ for $30 \mathrm{~min}$. The clean $\mathrm{Pd} / \alpha-\mathrm{Al}_{2} \mathrm{O}_{3}(0001)$ samples were then kept under pure Ar flow. Methylcyclohexane (MCH) was introduced into the flow reactor from an independent gas line using $\mathrm{Ar}$ as a carrier gas. Based on the vapor pressure, we estimate a partial pressure of $\mathrm{MCH}$ of 48 mbar. The total pressure of the reactants in the flow reactor was set to $1000 \mathrm{mbar}$ for each individual experiment with the flow rates set either to $5 \mathrm{ml} / \mathrm{min}$ (low flow) or to 100 $\mathrm{ml} / \mathrm{min}$ (high flow). All experiments were performed at a sample temperature of $500 \mathrm{~K}$.

For detailed analysis, the intensities of the Bragg reflections in the $2 \mathrm{D}$ reciprocal space maps were displayed on a logarithmic 
scale using a Matlab routine. This procedure magnifies minor diffraction patterns and allows to detect new phases with high accuracy. The logarithmic intensity profiles (Log 10 Intensities) were obtained from the $2 \mathrm{D}$ reciprocal space maps along radial direction and fitted with Voigt profiles.

\section{Results and Discussion}

3.1. $\mathrm{MCH}$ dehydrogenation over small Pd nanoparticles $(6 \mathrm{~nm})$ at low gas flow rate
A portion of the $2 \mathrm{D}$ reciprocal space map around the $\mathrm{Pd}(111)$ Bragg reflection obtained from the $6 \mathrm{~nm} \mathrm{Pd} / \alpha-\mathrm{Al}_{2} \mathrm{O}_{3}(0001)$ under $\mathrm{Ar}$ at a flow rate of $5 \mathrm{ml} / \mathrm{min}$ at $500 \mathrm{~K}$ is shown in Figure 1a. Analysis of the data was performed by monitoring the intensity profile of the $\mathrm{Pd}(111)$ Bragg reflection along the radial direction indicated by the red line in Figure 1a. The evolution of the intensity of the Bragg reflection under the exposure to two consecutive pulses of $\mathrm{MCH}$ at $500 \mathrm{~K}$ is plotted in Figure $1 \mathrm{~b}$ as a function of time and diffraction angle $2 \Theta$.
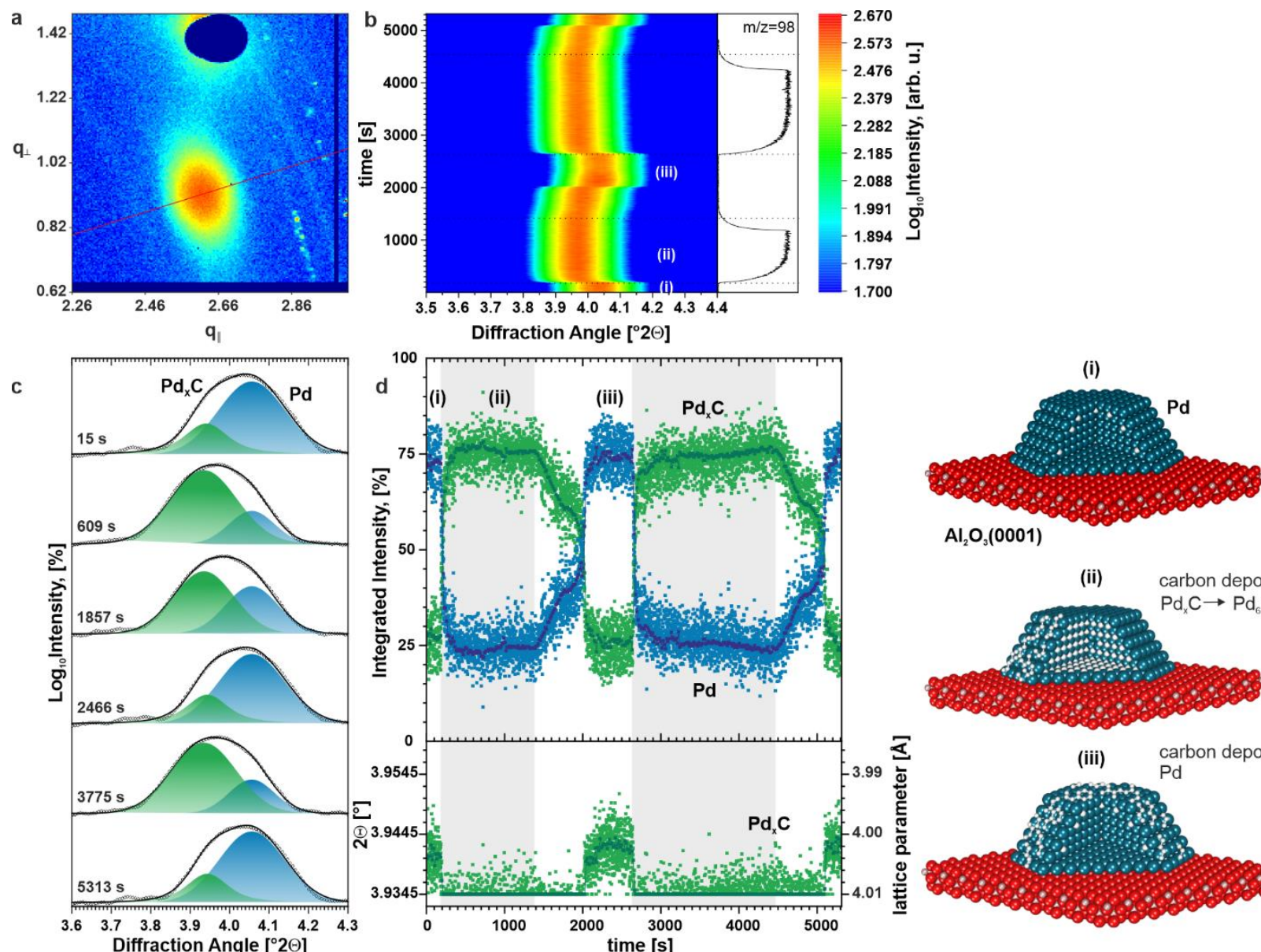

$\mathrm{Al}_{2} \mathrm{O}_{3}(0001)$

(ii) carbon deposits
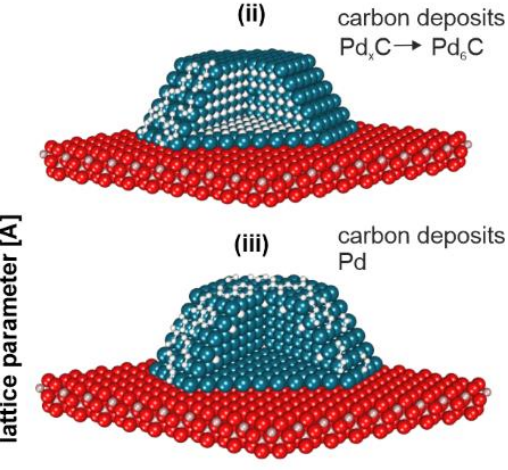

Figure 1. Small Pd nanoparticles (diameter $6 \mathrm{~nm}$ ) on $\alpha-\mathrm{Al}_{2} \mathrm{O}_{3}(0001)$ under a gas flow of $5 \mathrm{ml} / \mathrm{min}$ at $500 \mathrm{~K}$ : (a) Reciprocal space map around the $\mathrm{Pd}(111) \mathrm{Bragg}$ reflection. The red line indicates the direction of the radial intensity profile; (b) The intensity of the Pd(111) Bragg reflection and evolution of mass 98 associated with MCH as a function of time; (c) Selected intensity profiles of the $\mathrm{Pd}(111)$ Bragg reflection. (d) The fraction of pure $\mathrm{Pd}$ (blue) and $\mathrm{Pd}_{\mathrm{x}} \mathrm{C}$ (green) phases (top panel) and the position of the $\mathrm{Pd} \mathrm{d}_{\mathrm{x}} \mathrm{C}$ diffraction peak as a function of time. The grey boxes indicate the exposure to $\mathrm{MCH}$.

At the onset of the $\mathrm{MCH}$ flow, the Pd(111) Bragg peak shifts to lower diffraction angles. Then, the position of the peak remains constant under steady $\mathrm{MCH}$ partial pressure (Figure 1b). Subsequently, the feed was switched back to pure Ar, leading to a decrease of the $\mathrm{MCH}$ partial pressure. We observe that after a certain delay, the original position of the $\mathrm{Pd}(111)$ Bragg reflection is recovered. During the second $\mathrm{MCH}$ pulse, a similar behavior was observed. These observations suggest that structural changes in the supported $\mathrm{Pd}$ nanoparticles upon exposure of the catalyst to the reactant feed are highly reversible.
In order to obtain more detailed insights into the structure and phase composition of the Pd nanoparticles, we analyzed the intensity profile of the $\mathrm{Pd}(111)$ Bragg reflection. Selected profiles are shown in Figure 1c. Here, the profile obtained under Ar flow after the cleaning procedure is shown as the top trace. We resolved two peaks at diffraction angles of $4.056^{\circ}$ and $3.940^{\circ}$ yielding the lattice parameters of $0.389 \mathrm{~nm}$ and of 0.401 $\mathrm{nm}$ which are associated with the pure palladium and palladium carbide $\left(\mathrm{Pd}_{\mathrm{x}} \mathrm{C}\right)$ phases, respectively. ${ }^{36}$ Note that the formation of the $\beta$-hydride phase in supported $\mathrm{Pd}$ nanoparticles is suppressed at 500 K. ${ }^{24}$ The lattice parameter of the $\mathrm{Pd}_{\mathrm{x}} \mathrm{C}$ phase corresponds to an expansion of the Pd lattice by $3.1 \%$. For the 
fitting procedure, the position of the peak associated with the pure Pd phase was fixed. The component associated with the $\mathrm{Pd}_{\mathrm{x}} \mathrm{C}$ phase was allowed to vary between the values for pure $\mathrm{Pd}$ and $\mathrm{Pd}_{6} \mathrm{C} . \mathrm{Pd}_{6} \mathrm{C}$ is the palladium carbide phase with the highest carbon content $(14 \% \mathrm{C})$ reported in the literature. ${ }^{29,51}$

The evolution of the contributions of pure $\mathrm{Pd}$ and the $\mathrm{Pd}_{\mathrm{x}} \mathrm{C}$ phases is plotted in Figure $1 \mathrm{~d}$ as a function of time. The periods of time when the catalyst was exposed to $\mathrm{MCH}$ pulses are displayed as gray blocks. The fractions of pure $\mathrm{Pd}$ and $\mathrm{Pd}_{\mathrm{x}} \mathrm{C}$ phases were obtained by fitting intensity profiles obtained with an acquisition time of $1 \mathrm{~s}$. In order to improve the signal-tonoise ratio, we also averaged over 15 consecutive intensity profiles. The corresponding data are plotted in Figure 1d in darker colors.

The ball models in Figure 1 depict the phase composition of the small Pd nanoparticles in the experimental regions (i)-(iii). Thus, after the cleaning procedure the small Pd nanoparticles consist of predominantly of pure $\mathrm{Pd}$ with a minor amount of $\mathrm{Pd}_{\mathrm{x}} \mathrm{C}$. This phase composition remains stable under Ar flow (Figure 1, ball model (i)). As soon as $\mathrm{MCH}$ is added to the stream, the fraction of $\mathrm{Pd}_{\mathrm{x}} \mathrm{C}$ increases at the expense of the pure $\mathrm{Pd}$ phase. Eventually the majority of the material is transformed into the $\mathrm{Pd}_{\mathrm{x}} \mathrm{C}$ phase. This process is accompanied by a shift of the $\mathrm{Pd}_{\mathrm{x}} \mathrm{C}$ contribution to lower diffraction angles. The diffraction angle and the corresponding lattice parameter of the $\mathrm{Pd}_{\mathrm{x}} \mathrm{C}$ phase are plotted in Figure $1 \mathrm{~d}$ (bottom panel) as a function of time. We note that the $\mathrm{Pd}_{\mathrm{x}} \mathrm{C}$ contribution shifts from a diffraction angle of $3.940^{\circ}$ to $3.935^{\circ}$. The change in diffraction angle reflects an increasing carbon concentration, eventually approaching the value characteristic for the $\mathrm{Pd}_{6} \mathrm{C}$ phase. We assume that the $\mathrm{Pd}_{6} \mathrm{C}$ phase is covered by carbon deposits (Figure 1 , ball model (ii)). The formation of carbon deposits during dehydrogenation of LOHCs over Pd(111) and supported Pd nanoparticles above $450 \mathrm{~K}$ was observed earlier by means of high-resolution synchrotron radiation photoelectron spectroscopy studies. ${ }^{11,14}$ ${ }^{15}$ The $\mathrm{Pd}_{6} \mathrm{C}$ phase remains stable under $\mathrm{MCH}$ exposure. A similar behavior was previously reported in the literature. ${ }^{26-27,37,51-52}$ Subsequent exposure to pure Ar flow resulted in the decomposition of the $\mathrm{Pd}_{6} \mathrm{C}$ yielding the pure $\mathrm{Pd}$ phase. The decrease of the $\mathrm{Pd}_{6} \mathrm{C}$ signal is relatively slow at first and then rapidly accelerates indicating the transformation of the $\mathrm{Pd}_{6} \mathrm{C}$ into the $\mathrm{Pd}_{x} \mathrm{C}$ phase with lower carbon content. Note that the position of the $\mathrm{Pd}_{x} \mathrm{C}$ peak correlates linearly with the carbon content in the $\mathrm{Pd}_{x} \mathrm{C}$ phase. ${ }^{53}$ The phase transition is marked by the shift of the corresponding $\mathrm{Pd}_{\mathrm{x}} \mathrm{C}$ peak to higher diffraction angles which indicates a decrease of carbon content in $\mathrm{Pd}_{\mathrm{x}} \mathrm{C}$ (see Figure $1 \mathrm{~d}$, bottom panel, $2000 \mathrm{~s}$ ). Finally, the initial phase composition of the $\mathrm{Pd}$ nanoparticles is restored.

Note that at early stages of $\mathrm{Pd}_{6} \mathrm{C}$ decomposition, we did not observe the formation of any new $\mathrm{Pd}_{\mathrm{x}} \mathrm{C}$ phase. This observation suggests that carbon is removed out of the Pd nanoparticle by segregating to the surface. We believe that under reaction conditions, there is facile diffusion of carbon in both directions, i.e. into and out of the Pd nanoparticles. The stability of the $\mathrm{Pd}_{6} \mathrm{C}$ phase therefore depends on the rate of carbon formation and the rate of carbon removal by its reaction with hydrogen released into the gas phase during dehydrogenation of $\mathrm{MCH}$. In the absence of a carbon and hydrogen source from the gas phase, carbon segregates to the surface resulting in decomposition of the $\mathrm{Pd}_{6} \mathrm{C}$ phase which most likely contributes to the formation of carbon deposits. Typically, carbon deposits on Pd nanoparticles are found in the forms of carbon islands, carbon chains and filaments ${ }^{31}$ (Figure 1, ball model (iii)). It was reported that the carbon filaments are precursor to graphene. ${ }^{31}$ However, considering the high reproducibility of the phase composition of $\mathrm{Pd}$ nanoparticles under exposure to the second $\mathrm{MCH}$ pulse, we assume that the formation of graphene is not favorable under the applied experimental conditions.

\section{2. $\mathrm{MCH}$ dehydrogenation over small Pd nanoparticles $(6 \mathrm{~nm})$ at high gas flow rate}

In the next step, we investigated the behavior of the same sample, i.e. small Pd nanoparticles $(6 \mathrm{~nm})$ on $\alpha-\mathrm{Al}_{2} \mathrm{O}_{3}(0001)$, at a high gas flow rate of $100 \mathrm{ml} / \mathrm{min}$. The same sample was used as in the experiment described in Section 3.1 after applying an in-situ cleaning procedure (see Section 2). We note that the analysis of the FWHM of the $\mathrm{Pd}(111)$ Bragg reflection revealed no change in the Pd particle size after cleaning. The absence of new features in the 2D reciprocal map (Figure 2a) suggests full recovery of the catalyst after cleaning.

Generally, the conversion of $\mathrm{MCH}$ decreases with increasing flow rate. As a result, the concentration of hydrogen in the gas phase over the catalyst surface will also decrease. This means that less surface carbon will be removed by the reaction with hydrogen. In other words, carbon formation will be accelerated under high gas flow conditions. As a result, the nucleation of graphene may occur more easily due to a higher amount of carbon at the surface.

Upon exposure to $\mathrm{MCH}$ we observe that the $\mathrm{Pd}(111)$ Bragg reflection shifts to lower diffraction angles (Figure 2b). This behavior is very similar to that observed under exposure to $\mathrm{MCH}$ at a low gas flow rate. Remarkably, under longer exposure to $\mathrm{MCH}$, the reflection shifts slowly back to higher diffraction angles. Upon subsequent exposure to pure Ar, the diffraction angle remains practically unchanged (Figure $2 b$ ).

Similar as in section 3.1, the intensity profiles of the $\mathrm{Pd}(111)$ Bragg reflection were fitted with two contributions associated with the pure $\mathrm{Pd}$ and $\mathrm{Pd}_{\mathrm{x}} \mathrm{C}$ (Figure 2c). The evolution of the fractions of the two components is plotted in Figure $2 \mathrm{~d}$ as a function of time. The initial composition of the Pd nanoparticles is represented by a dominant contribution from the pure $\mathrm{Pd}$ phase and minor contribution from $\mathrm{Pd}_{\mathrm{x}} \mathrm{C}$ (Figure 2, ball model (i)). This phase composition is stable under Ar. Upon switching to $\mathrm{MCH}$, we observe a rapid increase of the $\mathrm{Pd}_{\mathrm{x}} \mathrm{C}$ contribution accompanied by its shift to lower diffraction angles. This observation indicates fast transformation into $\mathrm{Pd}_{6} \mathrm{C}$ (Figure 2, ball model (ii)). Noteworthy, the $\mathrm{Pd}_{6} \mathrm{C}$ is stable only for a short time at the high gas flow rate. As soon as the fraction of the $\mathrm{Pd}_{6} \mathrm{C}$ phase reaches maximum, the $\mathrm{Pd}_{6} \mathrm{C}$ phase starts to decompose yielding pure $\mathrm{Pd}$ covered by carbon deposits and graphene clusters (Figure 2, ball model (iii)). The fraction of the pure $\mathrm{Pd}$ phase gradually increases until the initial phase composition of clean $\mathrm{Pd}$ nanoparticles is nearly recovered 
(Figure 2, ball model (iv)). The corresponding trend suggests that initial phase composition of Pd nanoparticles followed by complete extraction of subsurface carbon will be achieved after longer times under Ar flow.

The evolutions of the fractions of the $\mathrm{Pd}_{\mathrm{x}} \mathrm{C}$ phases under low and high flow rates of $\mathrm{MCH}$ are plotted on the same time scale in Supporting Information (Figure $\mathrm{S} 3$ ). We propose that the differences in stability of the $\mathrm{Pd}_{6} \mathrm{C}$ phase at low and high flow rates of $\mathrm{MCH}$ result from the interplay between thermodynamic and kinetic effects during carbon deposition. We assume that under the conditions of low flow rate, the carbon deposition rate is lower due to partial removal of carbon by reaction with hydrogen from the gas phase and therefore is not sufficient for the nucleation of graphene. The situation changes at the high flow rate, where nucleation of graphene occurs approximately 120 seconds after starting the exposure to $\mathrm{MCH}$. This observation is consistent with accelerated carbon formation due to lesser removal of carbon by reaction with hydrogen under high flow. Following the nucleation of graphene, the $\mathrm{Pd}_{6} \mathrm{C}$ phase slowly decomposes due to segregation of carbon to the surface and its subsequent attachment to the growing graphene domains. ${ }^{39}$ It was reported that part of the segregated carbon accumulates at the graphene/Pd interface and also leads to growth of multilayer graphene. ${ }^{54}$ Our observation clearly shows that the $\mathrm{Pd}_{6} \mathrm{C}$ phase can be formed, but it is metastable under a high flow rate of $\mathrm{MCH}$.
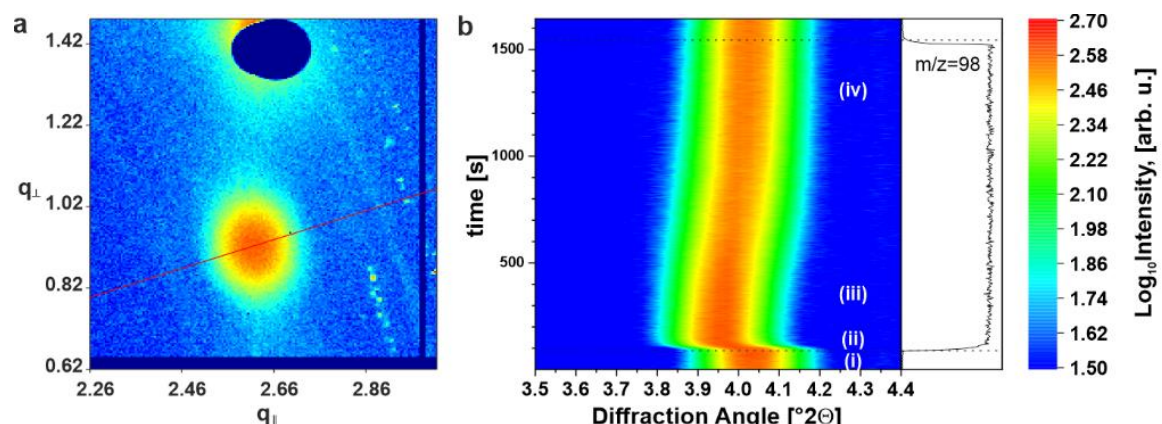

$\begin{array}{llllllllllll}3.5 & 3.6 & 3.7 & 3.8 & 3.9 & 4.0 & 4.1 & 4.2 & 4.3 & 4.4\end{array}$ Diffraction Angle [ $\left.{ }^{\circ} 2 \Theta\right]$
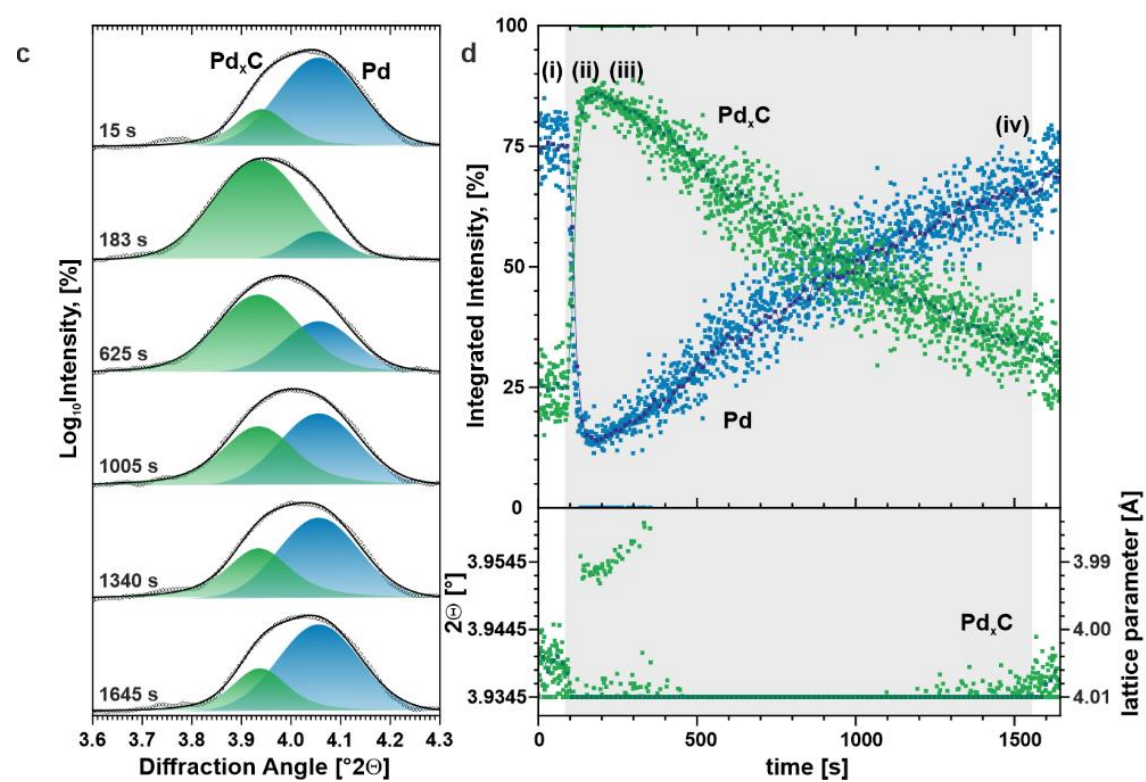
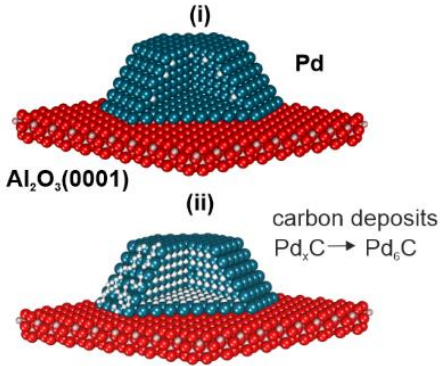

(iii)

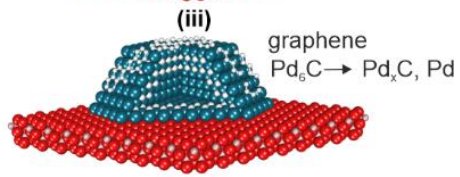

(iv)

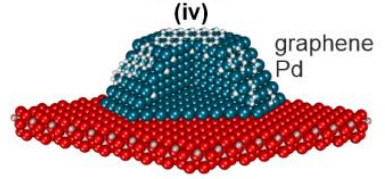

Figure 2. Small Pd nanoparticles (diameter $6 \mathrm{~nm}$ ) on $\alpha-\mathrm{Al}_{2} \mathrm{O}_{3}(0001)$ under a gas flow of $100 \mathrm{ml} / \mathrm{min}$ at $500 \mathrm{~K}$ : (a) Reciprocal space map around the Pd(111) Bragg reflection. The red line indicates the direction of the radial intensity profile; (b) The intensity of the $\mathrm{Pd}(111)$ Bragg reflection and evolution of mass 98 associated with $\mathrm{MCH}$ as a function of time; (c) Selected intensity profiles of the $\mathrm{Pd}(111)$ Bragg reflection. (d) The fraction of pure $\mathrm{Pd}$ (blue) and $\mathrm{Pd} \mathrm{x}_{\mathrm{C}} \mathrm{C}$ (green) phases as a function of time and $\mathrm{MCH}$ partial pressure. The grey box indicates exposure to $\mathrm{MCH}$.

\section{3. $\mathrm{MCH}$ dehydrogenation over big Pd nanoparticles $(15 \mathrm{~nm})$ at low gas flow rate}

Next, we investigated the influence of the particle size on the phase composition of the supported $\mathrm{Pd}$ nanoparticles. Considering a relatively large critical size of a graphene nucleus (about $5 \mathrm{~nm}$ as predicted on $\mathrm{Pd}(100)$ ), ${ }^{29}$ we expect that nucleation of graphene could be easier on the big $\mathrm{Pd}$ nanoparticles. In Figure 3, the corresponding data are displayed for big Pd nanoparticles (15 $\mathrm{nm} \mathrm{Pd}$ nanoparticles on $\alpha$ -
$\left.\mathrm{Al}_{2} \mathrm{O}_{3}(0001)\right)$. As for the experiments in sections 3.1 and 3.2, we show a 2D reciprocal space map around the $\mathrm{Pd}(111)$ Bragg reflection at $500 \mathrm{~K}$ (low Ar flow, $5 \mathrm{ml} / \mathrm{min}$ ) (Figure 3a). In addition to the sharp $\mathrm{Pd}(111)$ reflection from epitaxial $\mathrm{Pd}$ nanoparticles, we observed a Debye-Scherrer ring arising from randomly oriented (non-epitaxial) Pd nanoparticles. Similar as in sections 3.1 and 3.2, we performed an analysis of the intensity profile along the radial direction indicated by the red line in Figure 3a. In this way, we selectively analyzed the 
structure of $\mathrm{Pd}$ nanoparticles with a (111) epitaxy with respect to the $\mathrm{Al}_{2} \mathrm{O}_{3}(0001)$ surface. This allowed us to compare the structural changes in the epitaxial Pd nanoparticles as a function of size. The structural changes in non-epitaxial Pd nanoparticles derived from the intensity profile of the Debye-Scherrer ring in comparison to epitaxial Pd nanoparticles are discussed in the Supporting Information. Note that a crystal truncation rod (CTR) from the $\mathrm{Al}_{2} \mathrm{O}_{3}(0001)$ support (Figure $3 a$, white arrow) overlaps with the Bragg reflection from the $\mathrm{Pd}$ nanoparticles due to epitaxial in-plane orientation of Pd nanoparticles. ${ }^{55-56}$ We note that due to slightly different rotational angle, the CTR is not visible in the case of small Pd nanoparticles (Figures 1a, 2a). The intensity profile of the $\mathrm{Pd}(111)$ Bragg reflection is plotted in Figure $3 b$ as a function of time and diffraction angle $2 \Theta$.
Additionally, we compare the evolution of the fractions of $\mathrm{Pd}_{x} \mathrm{C}$ and $\mathrm{Pd}_{6} \mathrm{C}$ (and their sum, $\mathrm{Pd}_{6} \mathrm{C}+\mathrm{Pd}_{\mathrm{x}} \mathrm{C}$ ) for big $(15 \mathrm{~nm}$ ) and small $(6 \mathrm{~nm}) \mathrm{Pd}$ nanoparticles in Supporting Information (Figure S3). The differences are related to higher stability of the $\mathrm{Pd}_{\mathrm{x}} \mathrm{C}$ phases in the case of smaller $\mathrm{Pd}$ nanoparticles where the growth of graphene under the low flow rate of $\mathrm{MCH}$ is not favorable. In contrast to the small Pd nanoparticles, we observe a rapid shift of the Bragg reflection to higher diffraction angles at the onset of the $\mathrm{MCH}$ flow (at $\mathrm{t}=200 \mathrm{~s}$, Figure $3 \mathrm{~d}$ ). Then, the reflection gradually shifts to lower diffraction angles. The same shift is observed in the Debye-Scherrer ring (see Supporting Information for more detail). After a period of approximately $500 \mathrm{~s}$ in $\mathrm{MCH}$, the Bragg reflection broadens and the maximum gradually shifts back to higher diffraction angles.
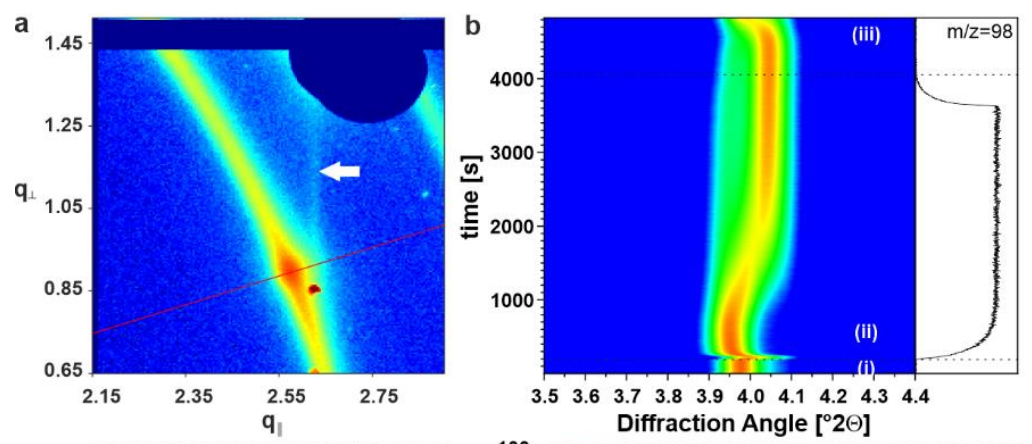

$\begin{array}{lllllllllll}3.5 & 3.6 & 3.7 & 3.8 & 3.9 & 4.0 & 4.1 & 4.2 & 4.3 & 4.4\end{array}$
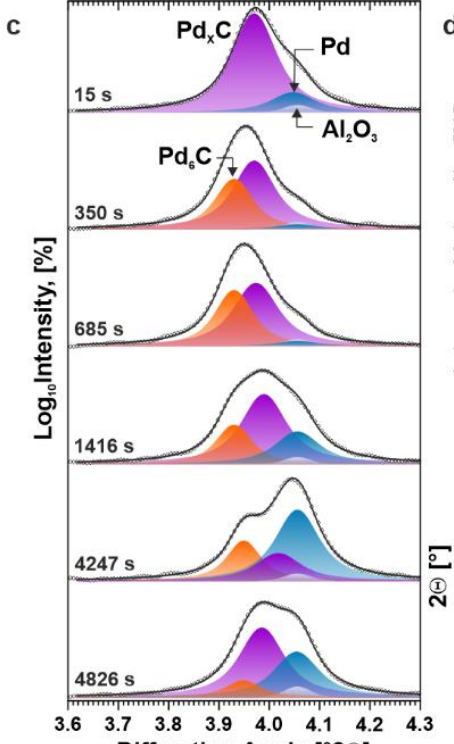
Diffraction Angle [ $\left.{ }^{\circ} 2 \Theta\right]$ Diffraction Angle [ $\left.{ }^{\circ} 2 \Theta\right]$

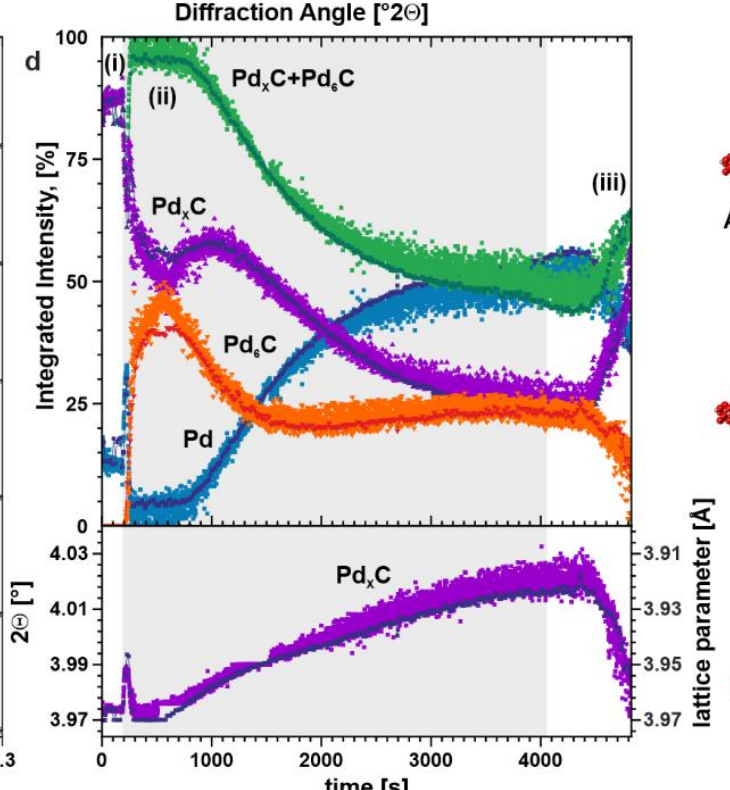

(i)

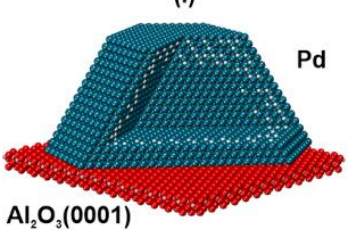

(ii)

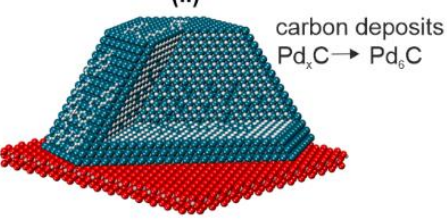

(iii)

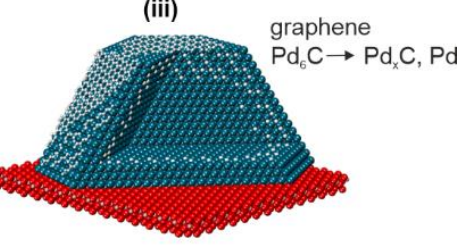

Figure 3. Big Pd nanoparticles (diameter $15 \mathrm{~nm}$ ) on $\alpha-\mathrm{Al}_{2} \mathrm{O}_{3}(0001)$ under a flow of $5 \mathrm{ml} / \mathrm{min}$ at $500 \mathrm{~K}$ : (a) Reciprocal space map around the $\mathrm{Pd}(111) \mathrm{Bragg}$ reflection. The red line indicates the direction of the radial intensity profile; The white arrow indicates the truncation rod from the $\alpha-\mathrm{Al}_{2} \mathrm{O}_{3}(0001)$ substrate; (b) The intensity of the $\mathrm{Pd}(111) \mathrm{Bragg}$ reflection and evolution of mass 98 associated with $\mathrm{MCH}$ as a function of time; (c) Selected intensity profiles of the $\mathrm{Pd}(111)$ Bragg reflection; (d) Fractions of pure $\mathrm{Pd}$ (blue squares), $\mathrm{Pd} \mathrm{d}_{6} \mathrm{C}$ (orange triangles), $\mathrm{Pd}_{\mathrm{x}} \mathrm{C}$ (purple triangles) phases, and the sum of the $\mathrm{Pd}_{6} \mathrm{C}$ and $\mathrm{Pd}_{\mathrm{x}} \mathrm{C}$ contributions (green squares) as a function of time. The grey box indicates exposure to $\mathrm{MCH}$.

Selected intensity profiles of the Bragg reflection are shown in Figure 3c. Here, the intensity profile obtained under Ar flow following the cleaning procedure is shown as the top trace. We resolved two peaks associated with the pure $\mathrm{Pd}$ and $\mathrm{Pd}_{\mathrm{x}} \mathrm{C}$ phases, respectively. The corresponding phase composition of $\mathrm{Pd}$ nanoparticles is schematically represented in Figure 3 (ball model (i)). The lattice parameter of the $\mathrm{Pd}_{\mathrm{x}} \mathrm{C}$ phase is $0.397 \mathrm{~nm}$ which corresponds to an expansion of the Pd lattice by $2.1 \%$.
Additionally, the contribution from the $\mathrm{Al}_{2} \mathrm{O}_{3}$ truncation rod was added to the fitting envelope (Figure $3 \mathrm{c}$, top). The position of this contribution was fixed and its intensity was allowed to vary by $\pm 20 \%$ during fitting.

We found that the rapid shift of the Bragg spot upon $\mathrm{MCH}$ exposure is caused by a shift of the $\mathrm{Pd}_{\mathrm{x}} \mathrm{C}$ contribution from a diffraction angle of $3.974^{\circ}$ to $3.994^{\circ}$ which corresponds to a change in the lattice parameter from 0.397 to $0.395 \mathrm{~nm}$. This 
observation suggests that a small amount of carbon rapidly segregated to the surface of the Pd nanoparticle. We suggest that upon $\mathrm{MCH}$ exposure, carbon is removed from the $\mathrm{Pd}$ nanoparticle by reaction with hydrogen formed upon dehydrogenation of $\mathrm{MCH}$. This process becomes less efficient upon progressive carbon deposition under a continuous flow of $\mathrm{MCH}$. Inward diffusion of carbon into the nanoparticles becomes dominant and the $\mathrm{Pd}_{\mathrm{x}} \mathrm{C}$ contribution shifts back to lower diffraction angle.

Notably, a new distinct component emerges at a diffraction angle of $3.930^{\circ}$. This feature can be assigned to the $\mathrm{Pd}_{6} \mathrm{C}$ phase. In contrast, the $\mathrm{Pd}_{x} \mathrm{C}$ phase in the Debye-Scherrer ring gradually transforms into the $\mathrm{Pd}_{6} \mathrm{C}$ phase without the emergence of any new peak (see Supporting Information, sections S4 and S5). The corresponding $2 \mathrm{D}$ reciprocal space map shows the splitting of both the Debye-Scherrer ring and the Bragg spot (Figure S6). Growth of the $\mathrm{Pd}_{6} \mathrm{C}$ phase is accompanied by a decrease of the signal from the pure $\mathrm{Pd}$ phase which eventually vanishes completely (Figure 3c, $350 \mathrm{~s}$ ). In the meantime, the two carbide phases, $\mathrm{Pd}_{6} \mathrm{C}$ and $\mathrm{Pd}_{\mathrm{x}} \mathrm{C}$, coexist. The corresponding phase composition is shown in Figure 3 (ball model (ii)). This observation is in a strong contrast to the small nanoparticles where only one type of carbide was detected at a given time. In Figure $3 \mathrm{~d}$, we show the evolution of fractions of $\mathrm{Pd}, \mathrm{Pd}_{6} \mathrm{C}$ and $\mathrm{Pd}_{x} \mathrm{C}$ (and the combined contributions from $\mathrm{Pd}_{6} \mathrm{C}$ and $\mathrm{Pd}_{\mathrm{x}} \mathrm{C}$ ). The broadening of the Bragg reflection (Figure $3 \mathrm{~b}$, at $\mathrm{t}>490 \mathrm{~s}$ ) under constant flow of $\mathrm{MCH}$ is caused by the reappearance of the pure $\mathrm{Pd}$ phase while the $\mathrm{Pd}_{6} \mathrm{C}$ phase is still present. The $\mathrm{Pd}$ component grows first at the expense of $\mathrm{Pd}_{6} \mathrm{C}$ and later at the expense of $\mathrm{Pd}_{x} \mathrm{C}$ (Figure $3 \mathrm{~d}$ ). Decomposition of $\mathrm{Pd}_{\mathrm{x}} \mathrm{C}$ is accompanied by a gradual shift of the corresponding contribution to higher diffraction angles (see Figure $3 d$, lower panel). Overall, the total contribution from the $\mathrm{Pd}_{6} \mathrm{C}$ and $\mathrm{Pd}_{\mathrm{x}} \mathrm{C}$ phases remains constant for about 500 seconds (Figure $3 \mathrm{~d}$ ) and decreases thereafter. We propose that this delay is caused by the nucleation of graphene. Once the graphene nucleus is formed, the carbide phases start to decompose due to segregation of carbon to the surface and subsequent attachment to the graphene deposits. ${ }^{39}$ It is noteworthy that the fraction of the $\mathrm{Pd}_{6} \mathrm{C}$ phase stops to decrease further at around $1700 \mathrm{~s}$. At this point only the $\mathrm{Pd}_{\mathrm{x}} \mathrm{C}$ phase is consumed and leads to further growth of the Pd phase (Figure $3 \mathrm{~d}$ ). The reason for this behavior is not clear. A possible explanation may involve the coexistence of differently shaped or sized nanoparticles on which the nucleation of the graphene phase is suppressed and, as a result, no carbon is extracted after the formation of $\mathrm{Pd}_{6} \mathrm{C}$. After switching back to a flow of pure $\mathrm{Ar}$, the phase composition of the supported $\mathrm{Pd}$ nanoparticles remains practically unchanged for approximately $400 \mathrm{~s}$. Then, the residual $\mathrm{Pd}_{6} \mathrm{C}$ starts to decompose yielding pure $\mathrm{Pd}$ and $\mathrm{Pd}_{\mathrm{x}} \mathrm{C}$ covered by carbon deposits and graphene (Figure $3 \mathrm{~d}$, model (iii)).

The size distribution of Pd nanoparticles after the exposure to $\mathrm{MCH}$ and $\mathrm{Ar}$ at $500 \mathrm{~K}$ was analyzed by SEM (see Supporting Information, Figure S2). Briefly, we found significant broadening of the size distribution resulting in the average diameter of $\mathrm{Pd}$ nanoparticles of $19.2 \pm 8.0 \mathrm{~nm}$. The corresponding density of $\mathrm{Pd}$ nanoparticles decreased to $3.4 \times 10^{14} \mathrm{~m}^{-2}$. This observation suggests sintering of $\mathrm{Pd}$ nanoparticles under operation conditions.

\section{Conclusions}

We have investigated the dynamic formation and decomposition of $\mathrm{Pd}$ carbides in a $\mathrm{Pd} / \alpha-\mathrm{Al}_{2} \mathrm{O}_{3}(0001)$ model catalyst by in-situ HE-GIXRD during dehydrogenation of a model liquid organic hydrogen carrier. The most important observations are listed below and are illustrated in Figure 4:

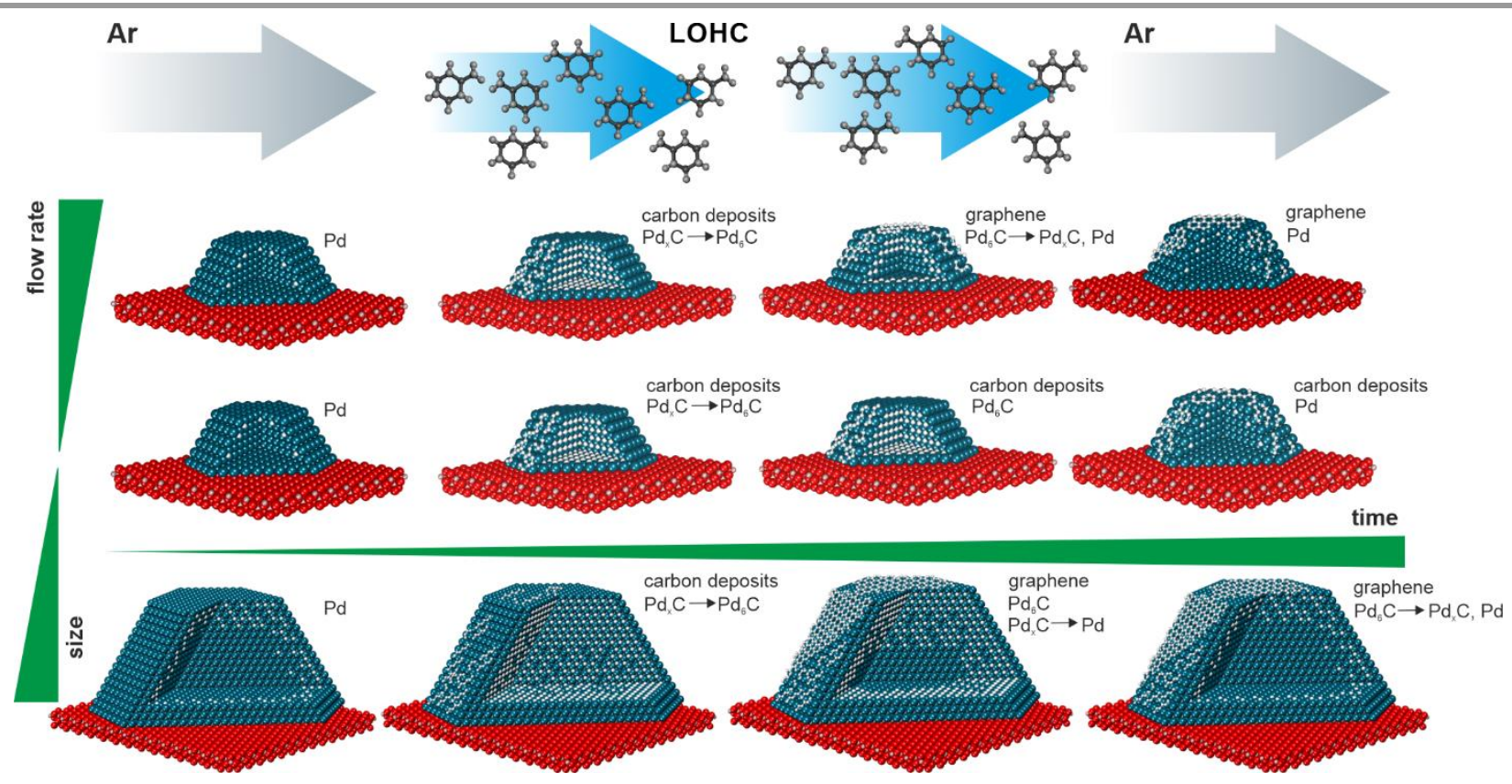


Figure 4. Schematic representation of the structural changes in the model $\mathrm{Pd} / \mathrm{Al}_{2} \mathrm{O}_{3}(0001)$ catalysts as a function of the flow rate of the reactant, size of supported Pd nanoparticles, and time of the catalyst on stream at $500 \mathrm{~K}$.

1) Exposure of small Pd nanoparticles $(6 \mathrm{~nm})$ to $\mathrm{MCH}$ at $500 \mathrm{~K}$ triggers the formation of a palladium carbide phase $\left(\mathrm{Pd}_{\mathrm{x}} \mathrm{C}\right)$. The carbon content in the $\mathrm{Pd}_{x} \mathrm{C}$ phase gradually increases yielding the $\mathrm{Pd}_{6} \mathrm{C}$ phase. The stability of the $\mathrm{Pd}_{6} \mathrm{C}$ critically depends on the composition of the reactant feed. At low $\mathrm{MCH}$ flow (i.e. high $\mathrm{H}_{2}$ partial pressure), the $\mathrm{Pd}_{6} \mathrm{C}$ phase is stable but decomposes in pure Ar. The stability of the $\mathrm{Pd}_{6} \mathrm{C}$ results from the balance between carbon formation and carbon consumption (mainly by reaction with hydrogen released upon the dehydrogenation of LOHC) under the flow of $\mathrm{MCH}$. In the absence of the carbon source from the gas phase, $\mathrm{Pd}_{6} \mathrm{C}$ decomposes due to carbon segregation to the surface of $\mathrm{Pd}$ nanoparticles. This behavior is fully reproducible upon repeated exposure to $\mathrm{MCH}$ under similar conditions. At a high flow rate of $\mathrm{MCH}$ (i.e. low $\mathrm{H}_{2}$ partial pressure), the $\mathrm{Pd}_{6} \mathrm{C}$ phase is formed but then rapidly decomposes. Decomposition of the $\mathrm{Pd}_{6} \mathrm{C}$ is triggered by the nucleation and growth of graphene deposits on the surface of Pd nanoparticles.

2) On larger Pd nanoparticles (diameter $15 \mathrm{~nm}$ ) a different behavior is observed. Upon exposure to $\mathrm{MCH}$, we observe the coexistence of two $\mathrm{Pd}$ carbide phases, i.e. $\mathrm{Pd}_{6} \mathrm{C}$ and $\mathrm{Pd}_{x} \mathrm{C}$. With increasing time on stream, the $\mathrm{Pd}_{\mathrm{x}} \mathrm{C}$ phase is converted to $\mathrm{Pd}_{6} \mathrm{C}$. Upon extended exposure to $\mathrm{MCH}$, we observe decomposition of the $\mathrm{Pd}_{6} \mathrm{C}$ and $\mathrm{Pd}_{\mathrm{x}} \mathrm{C}$ phases and the pure $\mathrm{Pd}$ phase is recovered. We propose that decomposition of the carbide occurs as a result of the formation of carbon deposits in the form of graphene. Because of slow nucleation, the graphene deposits are formed after an induction period.

Our results show that Pd catalysts may adopt very different states under conditions of LOHC dehydrogenation: The Pd nanoparticles may be present in the form of carbides with varying carbon content from $\mathrm{Pd}_{\mathrm{x}} \mathrm{C}$ up to $\mathrm{Pd}_{6} \mathrm{C}$ and in the form of pure $\mathrm{Pd}$ nanoparticles covered with graphene deposits. Formation and decomposition of these phases results from a complex interplay between their thermodynamic stability and the kinetics of carbon formation and consumption. The formation kinetics of the carbide phases strongly depends on the particle size. LOHC dehydrogenation is performed under dynamic operation conditions and the activation and deactivation phenomena which are typically observed in these processes are most likely related to dynamic formation of carbide phases.

\section{Conflicts of interest}

There are no conflicts to declare.

\section{Acknowledgements}

The authors acknowledge financial support from the Free State of Bavaria through its institutional and project-based support for the Helmholtz-Institute Erlangen-Nürnberg for Renewable Energies. The authors acknowledge additional financial support from the Federal Ministry of Education and Research (project
05K19WE1). The authors acknowledge financial support by the Deutsche Forschungsgemeinschaft (DFG) including the Cluster of Excellence "Engineering of Advanced Materials" (project EXC 315). Parts of this research were carried out at the DESY NanoLab, DESY, a member of the Helmholtz Association (HGF). Partial financial support by the DESY strategy fund (DSF) is acknowledged. We acknowledge the European Synchrotron Radiation Facility for provision of synchrotron radiation facilities and financial support. We thank Jan-Christian Schober for help in sample preparation and XRR analysis and Arno Jeromin for SEM analysis.

\section{Notes and references}

1 D. Teichmann, W. Arlt, P. Wasserscheid and R. Freymann, Energy Environ. Sci., 2011, 4, 2767-2773.

2 M. Niermann, S. Drünert, M. Kaltschmitt and K. Bonhoff, Energy Environ. Sci., 2019, 12, 290-307.

3 P. Preuster, A. Alekseev and P. Wasserscheid, Annu. Rev. Chem. Biomol. Eng., 2017, 8, 445-471.

4 L. Li, M. Yang, Y. Dong, P. Mei and H. Cheng, Int. J. Hydrogen Energy, 2016, 41, 16129-16134.

5 P. Preuster, C. Papp and P. Wasserscheid, Acc. Chem. Res. 2017, 50, 74-85.

6 M. Schwarz, P. Bachmann, T. N. Silva, S. Mohr, M. Scheuermeyer, F. Späth, U. Bauer, F. Düll, J. Steinhauer, C. Hohner, T. Döpper, H. Noei, A. Stierle, C. Papp, H.-P. Steinrück, P. Wasserscheid, A. Görling and J. Libuda, Chem. - Eur. J., 2017, 23, 14806-14818.

7 P. C. Rao and M. Yoon, Energies, 2020, 13, 6040.

8 A. Bulgarin, H. Jorschick, P. Preuster, A. Bösmann and P. Wasserscheid, Int. J. Hydrogen Energy, 2020, 45, 712-720.

9 P. M. Modisha, C. N. M. Ouma, R. Garidzirai, P. Wasserscheid and D. Bessarabov, Energy \& Fuels, 2019, 33, 2778-2796.

10 L. Zhou, L. Sun, L. Xu, C. Wan, Y. An and M. Ye, Catalysts, 2020, 10, 648 .

11 M. Amende, C. Gleichweit, T. Xu, O. Höfert, M. Koch, P. Wasserscheid, H. P. Steinrück, C. Papp and J. Libuda, Catal. Lett., 2016, 146, 851-860.

12 P. Bachmann, J. Steinhauer, F. Späth, F. Düll, U. Bauer, R. Eschenbacher, F. Hemauer, M. Scheuermeyer, A. Bösmann, M. Büttner, C. Neiß, A. Görling, P. Wasserscheid, H.-P. Steinrück and C. Papp, J. Chem. Phys., 2019, 151, 144711.

13 C. Gleichweit, M. Amende, O. Höfert, T. Xu, F. Späth, N. Brückner, P. Wasserscheid, J. Libuda, H.-P. Steinrück and C. Papp, J. Phys. Chem. C, 2015, 119, 20299-20311.

14 M. Amende, S. Schernich, M. Sobota, I. Nikiforidis, W. Hieringer, D. Assenbaum, C. Gleichweit, H.-J. Drescher, C. Papp, H.-P. Steinrück, A. Görling, P. Wasserscheid, M. Laurin and J. Libuda, Chem. - Eur. J., 2013, 19, 10854-10865.

15 M. Sobota, I. Nikiforidis, M. Amende, B. Sanmartín Zanón, T. Staudt, O. Höfert, Y. Lykhach, C. Papp, W. Hieringer, M. Laurin, D. Assenbaum, P. Wasserscheid, H.-P. Steinrück, A. Görling and J. Libuda, Chem. - Eur. J., 2011, 17, 11542-11552.

16 C. Gleichweit, M. Amende, U. Bauer, S. Schernich, O. Höfert, M. P. A. Lorenz, W. Zhao, M. Müller, M. Koch, P. Bachmann, P. Wasserscheid, J. Libuda, H.-P. Steinrück and C. Papp, J. Chem. Phys., 2014, 140, 204711.

17 M. Amende, C. Gleichweit, S. Schernich, O. Höfert, M. P. A. Lorenz, W. Zhao, M. Koch, K. Obesser, C. Papp, P. Wasserscheid, H.-P. Steinrück and J. Libuda, J. Phys. Chem. Lett., 2014, 5, 1498-1504. 
18 A. L. Bugaev, O. A. Usoltsev, A. Lazzarini, K. A. Lomachenko, A A. Guda, R. Pellegrini, M. Carosso, J. G. Vitillo, E. Groppo, J. A. van Bokhoven, A. V. Soldatov and C. Lamberti, Faraday Discuss., 2018, 208, 187-205.

19 D. Teschner, J. Borsodi, A. Wootsch, Z. Révay, M. Hävecker, A. Knop-Gericke, S. D. Jackson and R. Schlögl, Science, 2008, 320, 86.

20 D. Teschner, Z. Révay, J. Borsodi, M. Hävecker, A. KnopGericke, R. Schlögl, D. Milroy, S. D. Jackson, D. Torres and P. Sautet, Angew. Chem., Int. Ed., 2008, 47, 9274-9278.

21 K. M. Neyman and S. Schauermann, Angew. Chem., Int. Ed., 2010, 49, 4743-4746.

22 M. García-Mota, B. Bridier, J. Pérez-Ramírez and N. López, J. Catal., 2010, 273, 92-102.

23 M. W. Tew, M. Janousch, T. Huthwelker and J. A. van Bokhoven, J. Catal., 2011, 283, 45-54.

24 R. Schuster, F. Waidhas, M. Bertram, H. Runge, S. Geile, R. Shayduk, M. Abuín, V. Vonk, H. Noei, Y. Lykhach, F. Bertram, A. Stierle and J. Libuda, Catal. Lett., 2018, 148, 2901-2910.

25 M. Bowker, C. Morgan, N. Perkins, R. Holroyd, E. Fourre, F. Grillo and A. MacDowall, J. Phys. Chem. B, 2005, 109, 23772386.

26 H. Gabasch, K. Hayek, B. Klötzer, A. Knop-Gericke and R. Schlögl, J. Phys. Chem. B, 2006, 110, 4947-4952.

27 M. Morkel, V. V. Kaichev, G. Rupprechter, H. J. Freund, I. P. Prosvirin and V. I. Bukhtiyarov, J. Phys. Chem. B, 2004, 108, 12955-12961.

28 L. Gracia, M. Calatayud, J. Andrés, C. Minot and M. Salmeron, Phys. Rev. B, 2005, 71, 033407.

29 N. Seriani, F. Mittendorfer and G. Kresse, J. Chem. Phys., 2010, 132, 024711.

30 H. Grönbeck and C. Barth, J. Phys. Chem. C, 2019, 123, 43604370.

31 C. Barth, J. Phys. Chem. C, 2018, 122, 522-529.

32 O. Balmes, A. Resta, D. Wermeille, R. Felici, M. E. Messing, K. Deppert, Z. Liu, M. E. Grass, H. Bluhm, R. v. Rijn, J. W. M. Frenken, R. Westerström, S. Blomberg, J. Gustafson, J. N. Andersen and E. Lundgren, Phys. Chem. Chem. Phys., 2012, 14, 4796-4801.

33 F. Viñes, C. Loschen, F. Illas and K. M. Neyman, J. Catal., 2009 266, 59-63.

34 L. Nykänen, J. Andersin and K. Honkala, Phys. Rev. B, 2010, 81 075417.

35 S. M. Kozlov, I. V. Yudanov, H. A. Aleksandrov and N. Rösch, Phys. Chem. Chem. Phys., 2009, 11, 10955-10963.

36 S. B. Ziemecki, G. A. Jones, D. G. Swartzfager, R. L. Harlow and J. Faber, J. Am. Chem. Soc., 1985, 107, 4547-4548.

37 J. A. McCaulley, J. Phys. Chem., 1993, 97, 10372-10379.

38 J. A. McCaulley, Phys. Rev. B, 1993, 47, 4873-4879.

39 H. S. Mok, A. Ebnonnasir, Y. Murata, S. Nie, K. F. McCarty, C. V. Ciobanu and S. Kodambaka, Appl. Phys. Lett., 2014, 104, 101606.

40 A. Stierle, J. Gustafson and E. Lundgren, in Operando Research in Heterogeneous Catalysis, eds. J. Frenken and I. Groot, Springer International Publishing, Cham2017, pp. 59-87.

41 J. Gustafson, M. Shipilin, C. Zhang, A. Stierle, U. Hejral, U. Ruett, O. Gutowski, P. A. Carlsson, M. Skoglundh and E. Lundgren, Science, 2014, 343, 758-761.

42 U. Hejral, P. Müller, O. Balmes, D. Pontoni and A. Stierle, Nat Commun., 2016, 7, 10964.

43 U. Hejral, P. Müller, M. Shipilin, J. Gustafson, D. Franz, R. Shayduk, U. Rütt, C. Zhang, L. R. Merte, E. Lundgren, V. Vonk and A. Stierle, Phys. Rev. B, 2017, 96, 195433.

44 P. Nolte, A. Stierle, N. Kasper, N. Y. Jin-Phillipp, H. Reichert, A Rühm, J. Okasinski, H. Dosch and S. Schöder, Phys. Rev. $B$ 2008, 77, 115444 .
45 M. Shipilin, U. Hejral, E. Lundgren, L. R. Merte, C. Zhang, A Stierle, U. Ruett, O. Gutowski, M. Skoglundh, P.-A. Carlsson and J. Gustafson, Surf. Sci., 2014, 630, 229-235.

46 M. Shipilin, A. Stierle, L. R. Merte, J. Gustafson, U. Hejral, N. M. Martin, C. Zhang, D. Franz, V. Kilic and E. Lundgren, Surf. Sci., 2017, 660, 1-8.

47 P. Müller, U. Hejral, U. Rütt and A. Stierle, Phys. Chem. Chem. Phys., 2014, 16, 13866-13874.

48 R. van Rijn, M. D. Ackermann, O. Balmes, T. Dufrane, A. Geluk, H. Gonzalez, H. Isern, E. de Kuyper, L. Petit, V. A. Sole, D. Wermeille, R. Felici and J. W. M. Frenken, Rev. Sci. Instrum., 2010, 81, 014101.

49 A. Stierle, T. F. Keller, H. Noei, V. Vonk and R. Roehlsberger Journal of large-scale research facilities, 2016, 2, 1-9.

50 P. Scherrer, in Kolloidchemie Ein Lehrbuch, ed. R. Zsigmondy, Springer Berlin Heidelberg, Berlin, Heidelberg, 1912, pp. 387409.

51 S. B. Ziemecki, G. A. Jones and D. G. Swartzfager, J. LessCommon Met., 1987, 131, 157-162.

52 M. W. Tew, M. Nachtegaal, M. Janousch, T. Huthwelker and J. A. van Bokhoven, Phys. Chem. Chem. Phys., 2012, 14, 57615768.

53 R. H. Siller, R. B. McLellan and M. L. Rudee, J. Less-Common Met., 1969, 18, 432-433.

54 Y. Murata, S. Nie, A. Ebnonnasir, E. Starodub, B. B. Kappes, K. F. McCarty, C. V. Ciobanu and S. Kodambaka, Phys. Rev. B, 2012, 85, 205443.

55 K. Mašek and V. Matolín, Eur. Phys. J. D, 1999, 9, 557-560.

56 A. Aleman, C. Li, H. Zaid, H. Kindlund, J. Fankhauser, S. V. Prikhodko, M. S. Goorsky and S. Kodambaka, J Vac Sci Technol A, 2018, 36, 030602-030602. 